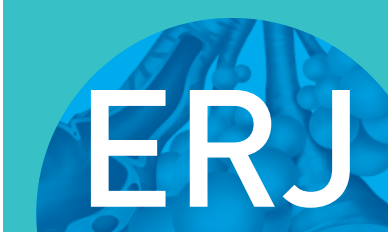

open research
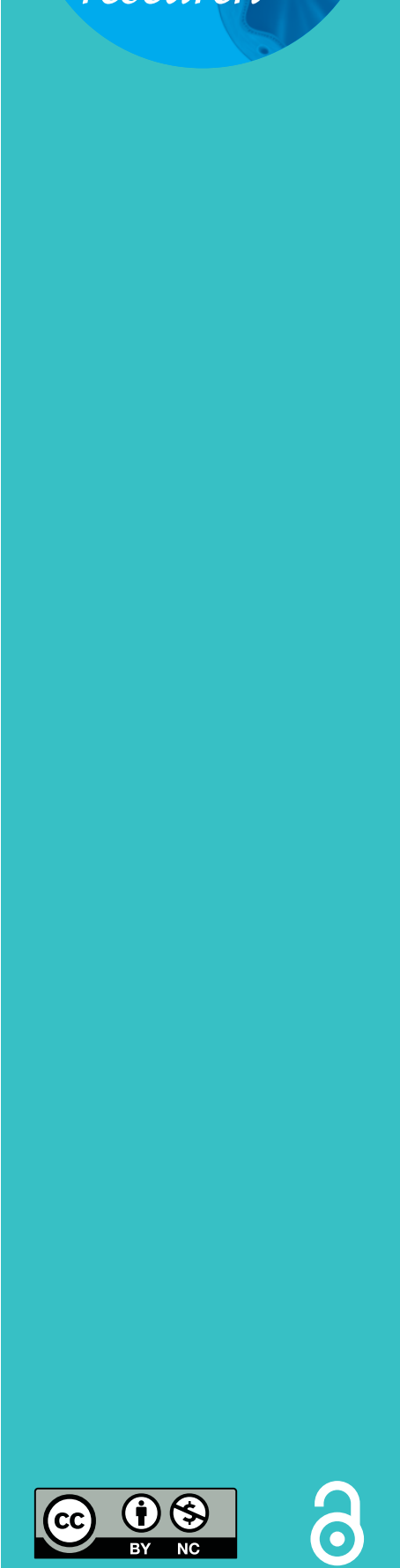

\section{ERS Presidential Summit: redesigning the future of patient care}

\author{
Mina Gaga \\ 7th Respiratory Medicine Dept, Athens Chest Hospital Sotiria, Athens, Greece.
}

Correspondence: Mina Gaga, 7th Respiratory Medicine Dept, Athens Chest Hospital Sotiria, 152 Mesogion Ave, Athens 15452, Greece. E-mail: minagagađyahoo.com

@ERSpublications

The ERS Presidential Summit is an annual event in the diary of the ERS President and leadership. The summit has the scope of raising awareness about lung health and disease, building alliances and helping better health. http://ow.ly/3Lt730lG31k

Cite this article as: Gaga M. ERS Presidential Summit: redesigning the future of patient care. ERJ Open Res 2019; 5: 00139-2018 [https://doi.org/10.1183/23120541.00139-2018].

The European Respiratory Society (ERS) Presidential Summit is an annual event in the diary of the ERS President and the ERS leadership. It is an occasion where the ERS President can select a topic of relevance to the respiratory field, but one that has a more societal focus and one that transcends boundaries between diseases. The summit has the scope of raising awareness about lung health and disease, building alliances and helping promote better health. It allows the leadership of the ERS, as well as key stakeholders in health, to look at an issue from a wider perspective, to learn from other disciplines, and to discuss and debate.

I wanted the 2018 summit to be a forum for discussion with patients at its core. Throughout the year we have been working on the ERS strategy up to 2025, discussing the emerging trends in medicine, their impact on society and how to help fulfil our aim; better lung health, prevention and alleviation of lung disease. So, we need to look at our environment, see and anticipate changes and redesign patient care, taking into consideration both the new changes and trends and, importantly, our patients' needs and expectations.

What are the trends and changes? Medicine is evolving, we are living in a fast-changing world, with many factors influencing medicine and the way it is practiced. These include revolutionary advances in technology leading to specialised and accurate diagnostics, new medications and personalised treatments and also a wealth of digital services and information. This leads to better care but also creates issues. People live longer so the population is ageing, there is multimorbidity and increased cost. We are also facing a new population of young people with multimorbidities and health issues from an early age. The Copenhagen Prospective Study on Asthma in Childhood (COPSAC) from Denmark involved a 35-year follow-up of 1.9 million children and demonstrated how one very positive medical step forward, the use of caesarean section to save the lives of babies in childbirth, has resulted in an increased number of comorbidities. The study showed increased risk of immune diseases such as asthma, leukaemia and inflammatory bowel disease in the C-section cohort, probably due to babies being born in a more sterile environment and not being exposed to different factors in the birthing canal [1]. In a seminal paper, Agusti et al. [2] also investigated the impact of early life events on health in later life. This study demonstrated a clear link between low lung function in early adulthood and respiratory, cardiovascular and metabolic issues in later life, and ultimately premature death. So, advances in medicine can both solve and create problems, for which we have to be aware.

This article has supplementary material available from openres.ersjournals.com

Received: Aug 282018 | Accepted: Aug 282018

Copyright $\odot E R S$ 2019. This article is open access and distributed under the terms of the Creative Commons Attribution Non-Commercial Licence 4.0. 
Further important issues in healthcare include healthcare disparities which are linked not only to the organisation of healthcare systems and the affluence of a country but importantly, to the level of education and socioeconomic status of each individual. A study from Belgium has shown that increases in life expectancy are still not evenly distributed across populations. Even in a country such as Belgium, BossuYT et al. [3] demonstrated that, at 20 years of age, people educated to primary level could expect 20-28 years of healthy living, those educated to secondary level could expect 38-42 years of healthy living, whereas those who had attended university could have up to 45 years of healthy living ahead of them. Education, a healthy lifestyle, screening of high-risk populations and a well-organised healthcare system may help overcome these disparities.

Digital technology may help delivery of healthcare; a recent article reported on the pilot trial of a health app in the UK. The app uses patient data to make online diagnoses and also provides video consultations with doctors and online prescriptions. The outcome of the pilot was that $80 \%$ of the diagnoses provided by the app were accurate [4]. There are clearly many concerns around this technology, including safety and accuracy, and favouring people who are technologically minded.

So, the changing medical landscape offers opportunities, as well as posing threats and risks. As a practicing clinician though, I realise on a daily basis that good healthcare requires not only knowledge but, importantly, empathy. It requires listening to patients, getting to know them and, within the limits of good medical practice, designing a management plan that fits their needs. Learning from our patients and seeing the disease from their point of view changes the way we think about disease and makes us try harder. Empathy is key in striving for and delivering the best for our patients.

Physicians were not used to working with patients. In September 1999, the BMJ published an edition entitled "embracing patient partnership" [5]. At the time this was a revolutionary idea. The journal discussed the concept of changing the doctor/patient relationship to be less paternalistic and to be more of a collaboration. 20 years on and the patient-professional relationship has changed, patients are active and involved not only in matters concerning their own health but in guidelines, in committees deciding access and reimbursement of medications and in advocacy. On a society level, nowhere can this be demonstrated as strongly as within the ERS. ERS has a unique position where patients can be actively involved via the European Lung Foundation (ELF; www.europeanlung.org). ELF provides an opportunity for European patient organisations in the respiratory field to debate, network and, most importantly, work together with healthcare professionals. It is with this backdrop that I decided to focus my summit on the needs of patients. I worked with Isabel Saraiva, ELF Chair, and Pippa Powell, ELF Director, on a survey which was sent to patients on the emerging trends in medicine. I also worked with Brian Ward and Marine Faure from the ERS Advocacy and European Affairs office in Brussels, to invite key stakeholders from academia, industry, the European Medicines Agency and the EU Health Commissioner, to see what the patients have to say, to give their perspective and discuss possible solutions.

TABLE 1 The four main areas identified by patient organisations as issues or trends in healthcare that are most important over the coming years

\begin{tabular}{ll} 
Key topic & Sample comments \\
\hline “Diseases" will change & We will be treated holistically as a person \\
We will live longer than ever before with one or more chronic \\
condition \\
Personalised medicine will be able to better define our conditions \\
and target treatments \\
We will be able to monitor, understand and manage our conditions \\
better using new technologies \\
Technology will help diagnose people with my condition quicker \\
Technologies \\
and easier \\
We will be able to talk to doctors online or access medical advice \\
in multiple ways, including social media \\
We will be consumers of healthcare, we may have to pay for it and \\
will expect better service \\
People will be as aware of the dangers of air pollution as they are \\
of tobacco \\
The public will understand the need for good lung health \\
throughout their lifetime and the impact of damage when young
\end{tabular}


What we wanted to find out and present in this summit was the patient perspective of the issues facing healthcare in the next 20 years. In order to do this, an email was sent out to 200 patient organisations who are part of the ELF patient organisation network. They were asked to complete a survey outlining what issues or trends in healthcare they thought would be most important over the coming years. Respondents were given 4 weeks to complete the survey. A total of 32 responses were received from the patient organisation network (16\% response rate). The key topics are presented in table 1.

The structure of the summit was designed using the topics proposed in the survey. Day 1 covered multidisciplinary and specialist care, multimorbidities and the ageing population and financing new advances in medical care. The second day of the summit was dedicated to a condition that is close to my heart, but also one which exemplifies a condition where lots of the issues debated in day one could be discussed in more detail, and that condition is lung cancer.

We were kindly invited by the ERJ Open Research editor to submit articles from this summit focusing on multimorbidities and the ageing population, financing new advances in medical care and lung cancer. A video summary of the event is available in the supplementary material.

This summit was important. It made us think about what is important to patients. What is clear to me is that we must be compassionate, offer personalised multidisciplinary care that is specialised, but that deals with a patient as a person and is holistic. However, we must be realistic about what can be achieved, and we must work together for affordable and sustainable healthcare.

Conflict of interest: M. Gaga has nothing to disclose.

\section{References}

1 Bisgaard H, Vissing NH, Carson CG, et al. Deep phenotyping of the unselected COPSAC2010 birth cohort study. Clin Exp Allergy 2013; 43: 1384-1394.

2 Agustí A, Noell G, Brugada J, et al. Lung function in early adulthood and health in later life: a transgenerational cohort analysis. Lancet Respir Med 2017; 5: 935-945.

3 Bossuyt N, Gadeyne S, Deboosere P, et al. Socio-economic inequalities in health expectancy in Belgium. Public Health 2004; 118: 3-10.

4 Science business. Your virtual doctor will see you now: AI app as accurate as doctors in $80 \%$ of primary care diseases. https://sciencebusiness.net/healthy-measures/news/your-virtual-doctor-will-see-you-now-ai-app-accuratedoctors-80-primary-care Date last updated: February 19 2018. Date last accessed: September 072018.

5 Take your partners for the dance. BMJ 1999; 319: https://doi.org/10.1136/bmj.319.7212.0. 